\title{
EFETIVIDADE CONSTITUCIONAL AO ALCANCE DE TODOS: UMA ANÁLISE DA SOCIEDADE CIVIL NA CONCRETIZAÇÃO DA CONSTITUIÇÃO FEDERAL DE 1988.
}

\author{
Maria Helena Ferreira Fonseca Faller
}

\begin{abstract}
Sumário: 1.Considerações iniciais;2.A crise da ConstituiçãoDirigentee a necessidade de resgate do sentido da política no Estado brasileiro; 2.1.O papel da sociedade civil; 3.Vontade de Constituição e Sociedade Pluralista de Intérpretes: efetividade constitucional possível; 4. Considerações Finais; Referências.
\end{abstract}

- Resumo: O presente artigo objetiva problematizar a discussão em torno da Teoria da Constituição Dirigente, evidenciando algumas de suas limitações, a partir de uma crítica realizada por autores que compreendem que para ocorrer efetividade constitucional é necessário resgatar o sentido da política no Estado Brasileiro, compreendida em seu sentido lato, abarcando assim os espaços públicos exteriores à esfera estatal. A partir disso, confere relevo ao papel da sociedade civil organizada no desenvolvimento da práxis constitucional, evidenciando as possibilidades de efetividade constitucional decorrentes do fortalecimento da vida política na sociedade brasileira, utilizando-se dos argumentos teóricos desenvolvidos por Konrad Hesse e Peter Haberle.

- Palavras- chave: Constituição Federal de 1988 - Efetividade constitucional - Crise da Teoria da Constituição Dirigente - Vontade de Constituição - Sociedade pluralista de intérpretes.

- Abstract: This article intend to turn problematic the debate around the Theory of the Constitution Governing, making evident some of its limitations, based on the critics made for some authors that understand that to occur constitutional effectiveness it is necessary to recover the sense of politics at Brazilian State, comprehended in a broad sense, environing all the publics spaces not included at the sphere of the State.As from that, confer prominence to the importance of the civil society organized on the development of the constitutional praxis, making evident all the possibilities for the constitutional effectiveness, originate from the encouragement of the public life in Brazilian society, making use of some theoretical argumentations elaborated by Konrad Hesse and Peter Haberle.

- Keywords: Federal Constitution of 1988- Constitutional Effectiveness - Crisis of the Theory of the Constitutional Governing - Constitution Will - Pluralist society of Interpreters.

\section{Considerações Iniciais}

O debate sobre a normatividade constitucional ocupa posição central nas atuais discussões constitucionais brasileiras. Após 21 anos de promulgação da Constituição Federal de 1988, é indiscutível o reconhecimento de uma forte ausência de efetividade constitucional.

Há, efetivamente, um abismo separando o discurso sobre a Constituição da efetiva operacionalização/concretização do Direito Constitucional. Vive-se em um contexto de baixa constitucionalidade, pelo esvaziamento da força normativa e do sequestro do sentido compromissório da Constituição (STRECK, 2004, p. 301).

\footnotetext{
* Mestre em Direito pela Universidade Federal de Santa Catarina, linha de pesquisa: Direito, Estado e Constituição, área de concentração: Direito, Estado e Sociedade. Professora de Teoria do Direito, Direito Constitucional e Direitos Sociais e Legislação Social das Faculdades Integradas do Brasil Unibrasil. Advogada e sócia de HydroFall Consultoria Ltda. Assessora Jurídica da Associação Nacional por uma Economia de Comunhão. Endereço eletrônico: mariahelena@faller.com.br.
} 
Nunca é repetitivo recordar que a Constituição Federal de 1988 é uma Constituição Dirigente ${ }^{1}$, elaborada no contexto do Constitucionalismo Social do século $\mathrm{XX}^{2}$, período caracterizado pela produção de textos constitucionais diretivos, direcionados a assegurar e a promover transformações sociais, a partir da previsão e da garantia de direitos sociais e de direcionamentos para as economias nacionais, objetivando realizar uma sociedade de bem-estar.

Nessas Constituições não apenas se formulam princípios políticos, como também normas sociais, em matéria de educação, economia, trabalho etc. (WOLKMER, 1989, p.19) Tais dispositivos constitucionais impóem ao Estado e a sociedade uma série de tarefas a serem realizadas. No caso do Brasil, se pode afirmar que estas "tarefas" impõem a operacionalização de grandes transformações na realidade política, social, econômica e cultural do país.

Contudo, já é possível constatar que não bastam normas constitucionais de conteúdo transformador inseridas em uma Constituição Dirigente para se operar, automaticamente, as mudanças sociais, políticas, econômicas e culturais por ela propostas. Uma Constituição não transforma a realidade pelo fato de existir no ordenamento jurídico, como se pode provar nestes 21 anos de vida da atual Carta Magna. Mesmo que se encontre em consonância com a realidade na qual está inserida, traduzindo os valores ali assentes, bem como as necessidades a serem concretizadas, são necessários outros elementos que possibilitem o desenvolvimento da práxis constitucional.

As discussões sobre este tema são extremamente complexas e diferenciadas.

Neste trabalho, será adotado como referencial teórico para o enfrentamento desta questão, autores que centram seus argumentos de efetividade no desenvolvimento de uma cultura de prática constitucional que se solidifica a partir da aceitação da assertiva de que a interpretação da Constituição se dirige a todos os

\footnotetext{
${ }^{1}$ Para a Teoria da Constituição Dirigente, a Constituição não é só garantia do existente, mas também um programa para o futuro. Ao fornecer linhas de atuação para a política, sem substituí-la, destaca a interdependência entre Estado e sociedade: a Constituição Dirigente é uma Constituição estatal e social. In: CANOTILHO, José Joaquim Gomes. Constituição Dirigente e vinculação do legislador: contributo para a compreensão de normas constitucionais programáticas. $2^{\mathrm{a}}$ ed. Coimbra: Coimbra Editora, 2001, p. 150-153.

${ }^{2}$ A passagem de um Constitucionalismo Político para outro Constitucionalismo de tipo social, refletiu uma tendência quase universal nas nações ocidentais. As Constituições políticas liberais - marcadas nitidamente pela natureza enunciativa e declaratória - refletiram a ascensão hegemônica de parcelas da sociedade civil sobre a estrutura de dominação absolutista do Estado. Já hodiernamente, as Constituições sociais tipificadoras de uma nova ordem política, que evidenciam a dinâmica do crescimento e do dirigismo estatal, são caracterizadas por um traço de conciliação e compromisso, em outro horizonte de interações entre Estado e segmentos societários. Sublinha-se que as necessárias e emergentes condições sócio-econômicas de fins de século XX propiciaram, no contexto de inúmeros sistemas políticos ocidentais, o patamar real para o surgimento também de Constituições ideológicas, marcadas por uma outra proposta político-jurídica e que, em certo grau de abstração, costumam ser inseridas num contexto maior, denominado Constitucionalismo Social. In: WOLKMER, Antonio Carlos. Constitucionalismo e Direitos Sociais no Brasil. São Paulo: Acadêmica, 1989, p. 16.
} 
membros do tecido social, os quais a concretizam quando vivem suas normas.

A partir disso, a Constituição recuperaria um elemento que lhe foi subtraído no decorrer do tempo, que é a conexão com a realidade social, política, cultural e econômica em que está inserida. Liberta-se das salas de tribunais e do legislativo para ganhar vida no desenvolvimento de um corpo político articulado, que resgata o sentido da política no Estado, por meio de articulações sociais e civis que buscam responsabilizar-se pelos espaços e problemas públicos, atuando de forma simultânea ao Estado. A sociedade civil ganha espaço e relevo nessa discussão, com a proposta a realização do resgate do sentido da política no Estado Brasileiro como espaço publico e extraestatal, capaz de operar grandes transformações sociais, como protagonista da ampliação da práxis constitucional.

Afinal, não obstante as críticas que se possam fazer aos trabalhos da Assembleia Nacional Constituinte de 1988 e ao texto constitucional resultante, não se pode olvidar o significado político, social, cultural que a Constituição Federal representou e representa na história política do país. Independentemente do referencial teórico que se parta, é indubitável que existe uma grande necessidade de se conferir materialidade aos direitos fundamentais ali previstos.

\section{A crise da Constituição Dirigente e a necessidade de resgate do sentido da política no Estado brasileiro}

Conforme já destacado, a realidade constitucional brasileira traz em evidência uma questão: não bastam as normas constitucionais para se mudar uma sociedade. A Constituição está em crise e no caso brasileiro, segundo Bercovici (2003, p. 75), esta crise é patente.

A Teoria da Constituição, talvez excessivamente preocupada com questões da interpretação constitucional e do controle de constitucionalidade, não consegue lidar de maneira satisfatória com os problemas políticos, sociais e econômicos inerentes à nova ordem constitucional em um país periférico. As soluções apresentadas situam-se sempre entre o instrumentalismo constitucional e a crença no Poder Judiciário como "salvador da República" ou adoção de concepções processuais da Constituição, limitada a um "instrumento de governo" ou uma "carta símbolo da identidade nacional" (BERCOVICI, 2003, p. 77).

Para resistir às críticas e às tentativas de enfraquecimento e desfiguração da Constituição vigente é necessário sair do instrumentalismo constitucional a que foi direcionada toda a reflexão constitucional brasileira pela adoção exageradamente acrítica da Teoria da Constituição Dirigente, que é uma teoria da Constituição autocentrada (BERCOVICI, 2005, p. 40-41):

[...] Ou seja, criou-se uma Teoria da Constituição tão poderosa, que a Constituição, por si só, resolve todos os problemas. O instrumentalismo constitucional é, desta forma, favorecido: acredita-se que é possível mudar a sociedade, transformar a realidade apenas com dispositivos constitucionais. Conseqüentemente, o Estado e a política são ignorados, deixados de lado. A 


\begin{abstract}
Teoria da Constituição Dirigente é uma Teoria da Constituição sem Teoria do Estado e sem política. E é justamente por meio da política e do Estado que a Constituição vai ser concretizada.
\end{abstract}

Ao reduzir a Teoria do Estado e da política, a Teoria da Constituição Dirigente, aliada ao momento histórico da globalização, facilitou, por mais paradoxal que possa parecer, a perda de substância da Constituição. Com a globalização, a redução dos espaços políticos faz com que o único elemento clarificador do horizonte político seja a Constituição (BERCOVICI, 2003, p. 120-121).

A necessidade de se resgatar o sentido da política na efetividade constitucional é patente. Bercovici (2003, p. 103-104), citando Hesse, afirma que a Constituição é a ordem jurídica da comunidade, ou seja, é a Constituição do Estado e da sociedade. A política se manifesta não apenas na instauração da Constituiçãocom o poder constituinte originário - mas também nos momentos seguintes, de efetivação da ordem constitucional por meio de uma política constitucional, que possibilite a práxis constitucional.

Nesse mesmo sentido, manifesta-se Lima (2006, p. 380):

\begin{abstract}
[...] é o fato de que o momento político das constituições e do direito constitucional somente ganha materialidade após a gênese constitucional, ou seja, concluído o processo constituinte é que as tensões políticas se formam e se revelam como desafio para toda a sociedade. Não afirmo que o instante constituinte esgota-se com o término de uma assembléia constituinte, mas penso que as proposições durante o processo constituinte possuem uma natureza distinta daquela de sua materialização com o passar dos anos.
\end{abstract}

A metodologia jurídica circunscrita ao material normativo cria uma concepção de que o Direito Constitucional recebeu todo o político e que tudo que é necessário para a compreensão do Estado está nas normas juŕdicas. Ignora-se a realidade política na qual se manifesta o direito constitucional e as valorações extrajurídicas não são entendidas como um problema do direito constitucional e da Teoria da Constituição, mas das demais ciências sociais (BERCOVICI, 2003, p. 122-123).

A política foi reduzida ao Poder Constituinte e este, relegado a segundo plano. A jurisdição constitucional foi alçada a garantidora da correta aplicação da normatividade, a única referência de legitimidade do sistema, refugando-se a doutrina na exegese das interpretações dos tribunais constitucionais (BERCOVICI, 2003, p. 123).

Ao contrário do que afirmam os tribunais, o Direito Constitucional não é monopólio do Judiciário. O direito constitucional e a interpretação constitucional são fruto de uma ação coordenada entre os poderes políticos, sociedade civil e o Judiciário. Nenhuma instituição, muito menos o Judiciário, pode conter a palavra final nas questões constitucionais (BERCOVICI, 2003, p. 125).

A pretensão dessa abordagem não é reduzir o papel fundamental ocupado 
pelo Poder Judiciário nessa discussão, mas inserir em seu contexto, conferindo-lhes a devida importância, elementos que foram relativizados ou subtraídos das discussões constitucionais. Afirma Bercovici (2003, p. 125):

As Constituições deixaram de ser entendidas como obra do povo para transformarem-se em criaturas de poderes misteriosos, metafísicos até. Sintomático é o fato, denunciado por autores como Olivier Beaud e Pedro Veja Garcia, que a teoria do Poder Constituinte, como máxima expressão do princípio democrático e como questão central da teoria constitucional foi relegado ao silencio pela Teoria da Constituição. O Poder Constituinte referese ao povo real, não ao idealismo jusnaturalista ou à norma fundamental pressuposta, pois diz respeito á força e autoridade do povo para estabelecer a Constituição, para mantê-la e revogála. O Poder Constituinte não se limita a estabelecer a Constituição, mas tem existência permanente, pois dele deriva a própria força normativa da Constituição.

Todos estes dilemas geram a perda do significado da Constituição para o povo e a Constituição só é real se significa algo para os cidadãos. Não se pode, portanto, entender a Constituição fora da realidade política, com categorias exclusivamente jurídicas. A Constituição não é exclusivamente normativa, mas também política; as questões constitucionais são também questões políticas. A política deve ser levada em consideração para a própria manutenção dos fundamentos constitucionais (BERCOVICI, 2003, p. 131).

Fechando os olhos para a realidade constitucional, segundo Bercovici (2003, p. 132), o pensamento jurídico positivista absolutizou as soluções constitucionais como atemporais. A Teoria da Constituição deve escapar desse engano, sendo compreendida na lógica das situações concretas históricas de cada país, integrando em um sistema unitário a realidade histórico-política e a realidade jurídica:

O direito constitucional recupera assim, segundo Pedro de Veja Garcia, as categorias de espaço e tempo e adquire dimensões concretas e históricas. A Constituição não pode ser entendida como entidade normativa independente e autônoma, sem história e temporalidades próprias. Não há uma Teoria da Constituição, mas várias Teorias da Constituição adequadas à sua realidade concreta. A Constituição não deve apenas estar adequada ao tempo, mas também ao espaço. Sem entender o Estado, não há como entender a Constituição, o que desqualifica a constante hostilidade da Teoria da Constituição contra o Estado. (BERCOVICI, 2003, p. 132)

Streck (2004, p. 317-333) segue o mesmo entendimento de Bercovici. Para ele, quando se fala em Constituição Dirigente, não se está a sustentar um normativismo constitucional (revolucionário ou não) capaz, de por si só, operar transformações emancipatórias. É necessário fixar-se com vigor na defesa da continuidade do perfil 
dirigente e compromissário da Constituição Federal, construindo o debate a partir daquilo que Streck vem denominando de Teoria da Constituição Dirigente Adequada a Países de Modernidade Tardia, a qual implica uma interligação com uma Teoria do Estado, visando à construção de um espaço público apto a implementar a Constituição em sua materialidade.

Dito de outro modo, uma tal Teoria da Constituição Dirigente não prescinde da teoria do Estado, apta a explicitar as condições de possibilidade para a implantação das políticas de desenvolvimento constantes - de forma dirigente e vinculativa - no texto da Constituição. Estado e Constituição estão umbilicalmente ligados (STRECK, 2004, p. 317).

É possível afirmar a continuidade da validade da tese da Constituição Dirigente, uma vez adequada a cada especificidade histórico-cultural de cada Estado Nacional. O dirigismo constitucional referido por Streck (2004, p. 335) é um conceito vinculado com a contemporaneidade que cerca a noção de Estado Nacional e que nada tem a ver com um "autismo nacionalista e patriótico":

\begin{abstract}
Na verdade, o que propugno é que os mecanismos constitucionais postos à disposição do cidadão e das instituições sejam utilizados, eficazmente, como instrumentos aptos a evitar que os poderes públicos disponham livremente da Constituição. A força normativa da Constituição não pode significar a opção pelo cumprimento ad hoc de dispositivos menos significativos da Lei Maior e o descumprimento sistemático daquilo que é mais importante - o seu núcleo essencial fundamental. É o mínimo a exigir, pois!
\end{abstract}

Streck e Bercovici possuem linhas de entendimento semelhantes. Para ambos, a crise da Teoria da Constituição só será superada com a efetiva politização e o retorno à Teoria do Estado. Entende Bercovici (2003, p. 135) que o resgate da política no Estado Brasileiro possibilita a concretização constitucional. A crise da Teoria da Constituição pode ser superada se compreendida a Constituição em conexão com a política e a realidade social:

\footnotetext{
Entender a Constituição como não apenas normativa, mas também política. Compreender as relações políticas e sociais presentes nas estruturas constitucionais. Perceber que a Constituição pertence também à realidade histórico-social. Tornar claros os nexos existentes entre Estado, Constituição e política, concebendo o direito constitucional como direito político.
}

Entende-se que o resgate da política no Estado Brasileiro, proposto por Bercovici, consiste não apenas na reconsideração da Teoria do Estado, mas também do sentido da política compreendida em sentido lato, conforme propõe Pateman (1992, p. 140-141): como espaço público também exterior à esfera estatal. 
Vieira (2001, p. 30) afirma que a ascensão de forças sociais no plano global constitui um tipo novo e diferente de política, a ideia de política cívica, a qual propõe que, enraizado nas atividades de associações civis, se encontra um entendimento de que os Estados não detêm o monopólio dos instrumentos que governam os negócios humanos e que, ao contrário, existem formas não-estatais de governança que podem ser usadas em larga escala. A análise que será proferida a seguir se centralizará nesse sentido.

Não obstante a necessidade de se discutir o papel dos Poderes Públicos como elementos para uma nova compreensão e fortalecimento da Teoria da Constituição Dirigente, neste trabalho, será analisado, pormenorizadamente, o papel da sociedade civil e da comunidade como impulsionadores de uma política de práxis constitucional. A política desenvolvida nas esferas exteriores ao Estado possui um grande poder de revitalizar articulações sociais, no presente caso, articulações que promovam a ampliação da práxis constitucional.

É justamente neste sentido a assertiva de Lima (2006, p. 381). Afirma o autor que o discurso constituinte possui certo grau de idealidade. Contém proposições inovadoras que insinuam que sua eficácia somente se confirmará por intermédio do acúmulo futuro da experiência política que daí decorrerá. O desgaste das Constituições Dirigentes latino-americanas dos anos 80 não é decorrente da distância entre norma e realidade, mas por inexistir, nas respectivas sociedades, forças políticas e sociais comprometidas com a efetividade constitucional ou mesmo forças para fazer frente aos processos "des-emancipatórios" em desenvolvimento.

Para Lima (2006, p. 381), a realidade política e social dos países latinoamericanos exige novamente dessas sociedades a mobilização política e contínua de seus atores que histórica e objetivamente insistiram na construção da democracia constitucional:

\begin{abstract}
Essa mobilização emancipatória somente permanecerá na sua condição original por meio da busca do realismo constitucional, possível de ser detectado em cada uma das distintas realidades políticas construídas pelas constituições dirigentes, e sob governos que se reivindiquem transformadores, se recorre-se ao realismo da política. [...] a sobrevivência de uma constituição dirigente depende também do convencimento da sociedade de que esta constituição ainda vigora e que sua simbologia referencial não foi esquecida. Naturalmente que o raio de uma tal ação política inclui instrumentos da sociedade-intelectuais, partidos políticos por exemplo-mas também engloba setores do próprio Estado. (LIMA, 2006, p. 381)
\end{abstract}

É sobre as possibilidades e alternativas apresentadas por essas forças políticas e sociais comprometidas com a efetividade constitucional que se pretende debruçar a partir de então, ressaltando, de plano, que tal opção não significa ignorância acerca da fundamentalidade do papel do Estado nessa discussão. Trata-se apenas de um 
recorte teórico. Para tanto, será feita uma reflexão acerca do conceito de sociedade civil como espaço público possibilitador de práticas sociais, políticas e culturais emancipatórias.

\title{
2.1. O papel da sociedade civil
}

A comunidade, bem como, a sociedade civil possui grande força potencializadora de transformações sociais. Para tanto, é necessário que se reconheçam como tais e se articulem como tais. O esquecimento constitucional delata uma questão muito mais ampla, que vai além de questões meramente jurídicas. Trata-se de um esquecimento da importância da política, de uma vida civil, de responsabilidade comunitária. Afinal, o conteúdo constitucional é tradução de muitos valores sociais e culturais assentes na sociedade brasileira.

Não se pretende discorrer sobre o caráter excludente do atual estado de coisas acentuado pela globalização, já que a evidência dos dados econômicos sugere de maneira razoavelmente clara que a concentração de renda em favor das sociedades ricas aumenta cotidianamente. $\mathrm{O}$ que se pretende discutir é sobre a possibilidade de confronto com as exigências econômicas dos mercados globalizados, na necessidade de um acúmulo concreto de forças políticas em torno de um projeto de emancipação como base na Constituição Dirigente, o que se apresenta como um grande viabilizador de fidelidade política ao texto constitucional (LIMA, 2006, p. 383).

Santos (2006, p. 342) afirma a importância desse resgate do sentido da vida comunitária e civil:

\begin{abstract}
A institucionalidade reformista traduziu-se numa articulação específica entre três pilares de regulação da modernidade: o princípio do Estado, o princípio do mercado e o princípio da comunidade. Estabeleceu-se um círculo vicioso entre o princípio do Estado e o princípio do mercado de que ambos saíram reforçados, enquanto o principio da comunidade, assente na obrigação política horizontal cidadão a cidadão, foi totalmente descaracterizado na medida em que o reconhecimento político da cooperação e da solidariedade entre cidadãos foram restringidos às formas de cooperação e de solidariedade mediadas pelo Estado.
\end{abstract}

Nesse sentido, pode-se afirmar que se operou uma redução do espaço político apenas aos espaços estatais, desnaturando a capacidade transformadora que as articulações políticas emergidas da sociedade civil possuem.

Citando Rosseau, Santos (2006, p. 352) aduz que o princípio da comunidade é o indispensável contraponto ao princípio do Estado, vez que enquanto o princípio do Estado estabelece a obrigação política de forma vertical entre Estado e cidadãos, o princípio da comunidade afirmava a obrigação política horizontal e solidária de 
cidadão a cidadão. $\mathrm{O}$ ressurgimento do terceiro setor ${ }^{3}$ no final do século $\mathrm{XX}$ representa, para o autor, a oportunidade para o princípio da comunidade comprovar seu papel fundamental.

Com efeito, nas condições atuais, em face das graves implicações sociais da globalização econômica, o Estado não parece interessado em incentivar a mobilização popular, mantendo a cidadania passiva e política. Como ao mercado não interessa outra coisa, cabe à sociedade civil, agrupada em torno do interesse público, a tarefa de mobilizar energias cívicas da população para defender os princípios da cidadania, fertilizados com os ideais de democracia política, diversidade cultural e sustentabilidade ambiental (VIEIRA, 2001, p. 29).

Apesar do abalo que vem sofrendo a cidadania pelo declínio do Estado territorial e da soberania nacional, a atuação transnacional das organizações da sociedade civil na salvaguarda da democracia e dos direitos humanos, bem como a luta pelo desenvolvimento sustentável e pela diversidade cultural, parece indicar que está em curso a tendência de constituição de uma sociedade civil global (VIEIRA, 2001, p. 29).

Vieira (2001, p. 34) apresenta duas concepções clássicas de sociedade civil: a de origem durkheimiana e de origem marxista. A primeira concebe a sociedade civil como a esfera pública, formada por grupos voluntários, privados e sem fins lucrativos. A segunda, por sua vez, compreende a sociedade civil como todas as organizações e atividades fora do Estado, inclusive, as atividades econômicas das empresas.

A atual referência à sociedade civil, segundo Vieira (2001, p. 34), traz o viés gramsciano ${ }^{4}$ de proteção contra os abusos estatais e do mercado e pode ser compreendida como uma intermediação entre o enfoque eminentemente estatal (adotado por Thomas H. Marshall) ${ }^{5}$ e o enfoque da virtude cívica centrada na sociedade, característica das teorias durkheimianas.

É importante registrar que, para Vieira (2001, p. 37) as noções de cidadania e sociedade civil são empiricamente contingentes, embora possuam noções diferentes. A cidadania é reforçada pelo Estado e a sociedade civil cria grupos em harmonia ou conflito:

A sociedade civil cria grupos e pressiona em direção a opções políticas, produzindo, consequentemente, estruturas institucionais que favorecem a cidadania. [...] Além disso, a

\footnotetext{
${ }^{3}$ Santos (2006, p. 350) define terceiro setor como uma designação residual e vaga com que se pretende dar conta de um vastíssimo conjunto de organizações sócias que não são nem estatais, nem mercantis, ou seja, organizações sociais que, por um lado, sendo privadas, não visam lucro, e por, outro lado, sendo animadas por objetivos sociais, públicos ou coletivos, não são estatais. Exemplos: cooperativas, associações mutualistas, organizações comunitárias, de base etc.

${ }^{4}$ Eis a concepção a partir da qual se trabalhará a sociedade civil neste artigo.

${ }^{5}$ Em 1949, Marshall propôs a primeira teoria sociológica de cidadania ao desenvolver os direitos e obrigações inerentes à condição de cidadão. Centrado na realidade britânica da época, em especial no conflito frontal entre capitalismo e igualdade, Marshall estabeleceu uma tipologia dos direitos de cidadania, quais sejam: os direitos civis e os direitos políticos, ambos chamados de direitos de primeira geração e os direitos sociais, chamados direitos de segunda geração (VIEIRA, 2001, p. 32).
} 
sociedade civil consiste primordialmente na esfera pública, onde associações e organizações se engajam em debates, de forma que a maior parte das lutas pela cidadania são realizadas em seu âmbito por meio dos interesses dos grupos sociais, embora cabe a ressalva - a sociedade civil não possa constituir o locus dos direitos de cidadania, por não se tratar da esfera estatal, que assegura proteção oficial mediante sanções legais. (VIEIRA, 2001, p. 37)

Ressalva-se que o termo sociedade civil é alvo de ampla discussão. Não se irá aprofundar a questão, por não ser este o objeto do presente estudo. O que é importante denotar é o potencial que a sociedade civil possui de fomentar e recriar os espaços públicos, de desenvolvimento político e comunitário.

Os processos de reprodução sociocultural se convertem em forma política no espaço público. As associações civis absorvem iniciativas sociais difusas, encaminhando-as para espaço público para o embate político. As associações e os movimentos sociais ampliam o espectro do político, incorporando novos temas na agenda política, desempenhando, assim, papel fundamental na construção do espaço público (VIEIRA, 2001, p. 73).

O resgate do sentido da política proposto por Bercovici (2003), por Streck (2004) e por Lima (2006) para salvaguardar a efetividade da Constituição Dirigente de 1988 encontra ampla consonância com esta discussão acerca do papel da sociedade civil como possibilitadora de recriação dos espaços de vida pública. Indivíduos possuem pouca força e expressão. Uma articulação de pessoas e grupos atinge grande expressividade e pode criar opções políticas favoráveis ao compromisso constitucional.

A Constituição Federal possui força normativa, contudo, necessita, para alcançar legitimação material, do desenvolvimento da política dentro do Estado Brasileiro, como possibilidade de organização e mobilização para reflexão e busca de objetivos de interesse comum. Grupos de pessoas organizados, associações de caráter civil, podem orientar suas condutas ao determinado constitucionalmente, conferindo legitimidade material ao texto constitucional, mas o fazem conjuntamente, em torno de um projeto comum, que os motiva e os leva a construir um espaço político eminentemente transformador da realidade.

A sociedade civil assim entendida possui amplas possibilidades de influenciar a classe política, concebida como aquela que representa a sociedade dentro das estruturas estatais e contribuir para a reformulação do próprio Estado (VIEIRA, 2001, p. 77-79).

Assevera Vieira (2001, p. 79, grifo do autor):

Não se trata apenas de pressionar o Estado, para reivindicar direitos, mas de modernizar a própria sociedade civil, transformando as estruturas tradicionais de dominação, exclusão e desigualdade que, fora do aparelho de Estado, se encontram enraizadas nas instituições, normas, valores e identidades coletivas, baseadas em preconceitos de raça, classe, e gênero, configurando o que Foucault denominou de 'micropoderes'. 
Esse elemento político articulador cria e recria entre as pessoas uma "vontade de Constituição" e é essencial para que ocorra efetividade constitucional. A política desenvolvida nesse sentido proporciona a ocorrência de um maior reconhecimento dos destinatários da Carta com o conteúdo do texto constitucional.

Afinal, a responsabilidade pela construção do Estado Democrático de Direito é de toda a sociedade, não somente dos Poderes Públicos.

\section{Vontade de Constituição e Sociedade Pluralista de Intérpretes: efetividade constitucional possível.}

A discussão acerca da força normativa e da efetividade constitucional não é recente. A teoria de Konrad Hesse, analisada a seguir, avança no sentido de apresentar um importante elemento para a realização constitucional, que possui conexão com as temáticas aventadas anteriormente: a vontade de Constituição, a qual possibilita e responsabiliza a todos os membros de uma sociedade a efetivarem a Constituição mediante a conformação direta de seus comportamentos ao contido na Lei Fundamental.

Haberle, por sua vez, ao apresentar sua teoria da "Sociedade Pluralista de Intérpretes da Constituição" contribui nessa discussão quando amplia o círculo de interpretação constitucional para toda a sociedade, responsabilizando a todos pela vivência da Constituição e reconhecendo nesta vivência uma legítima interpretação constitucional.

Embora possuam aportes teóricos diversos, ambos os autores, possuem uma importante característica em comum: ampliam a discussão sobre a interpretação constitucional para além dos limites estatais, responsabilizando toda a sociedade pela vivência constitucional. Para uma sociedade conseguir dinamizar-se a esse ponto, deve ocorrer um fortalecimento dos espaços políticos, no sentido abordado anteriormente neste artigo.

Inicia-se a reflexão por Hesse. Ainda no século XIX, em 16 de abril de 1862, Ferdinand Lassale proferiu uma conferência sobre a essência da Constituição. Afirmou que esta constituição formal, escrita, nominada de Constituição Jurídica, tratava-se de mero pedaço de papel. A verdadeira constituição de um país eram os fatores reais de poder que regiam esta nação. A Constituição escrita - Jurídica - constituía um mero pedaço de papel que deveria apenas retratar a constituição real de um país. Do contrário, sucumbe à realidade (LASSALE, 1987, p. 08).

Konrad Hesse, em sua aula inaugural ministrada na Universidade de Freiburg -RFA no ano de 1959, contrapõe os argumentos de Lassale com sua teoria intitulada 'Força Normativa da Constituição'.

Hesse (1991, p. 10) afirma que a história constitucional parece, efetivamente, ensinar que, tanto na práxis política cotidiana quanto nas questões fundamentais do Estado, o poder da força afigura-se sempre superior à força das normas jurídicas, que a normatividade submete-se à prática: 


\begin{abstract}
Considerada em suas conseqüências, a concepção da força dominante das relações fáticas, significa o seguinte: a condição de eficácia da Constituição jurídica, isto é, a coincidência entre realidade e norma, constitui apenas um limite hipotético extremo. É que entre a norma fundamentalmente estática e racional e a realidade fluída e irracional, existe uma tensão necessária e imanente que não se deixa eliminar. Para essa concepção de Direito Constitucional, está configurada permanentemente uma situação de conflito: a Constituição jurídica, no que tem de fundamental, isto é, nas disposições não propriamente de índole técnica, sucumbe cotidianamente em face da Constituição real. A idéia de um efeito determinante exclusivo da Constituição real não significa outra coisa senão a própria negação da Constituição jurídica. [...] Essa negação do Direito Constitucional importa na negação do seu valor enquanto ciência jurídica. [...]. Assim, o Direito Constitucional não estaria a serviço de uma ordem estatal, cumprindo-lhe tão somente a miserável função - indigna de qualquer ciência - de justificar as relações de poder dominantes. Se a Ciência da Constituição adota essa tese e passa a admitir a Constituição real como decisiva, tem-se a sua descaracterização como ciência normativa, operando-se a sua conversão numa simples ciência do ser. Não haveria mais como diferenciá-la da Sociologia ou da Ciência Política. (HESSE, 1991, p.10)
\end{abstract}

Porém, entende este autor que se configura justamente o contrário. Partindose da premissa que a Constituição contém, ainda que de forma limitada, uma força própria, motivadora e ordenadora da vida do Estado, admite-se que ela possui força normativa. Essa força reside justamente no condicionamento recíproco existente entre a Constituição jurídica e a realidade político-social, que devem ser compreendidas em sua totalidade, superando o pensamento constitucional do passado, o qual estava marcado pelo isolamento entre norma e realidade (HESSE, 1991, p. 13).

A norma constitucional não tem existência autônoma em face da realidade. A sua essência reside na sua vigência, ou seja, a situação por ela regulada deve ser concretizada na realidade. Essa pretensão de eficácia não pode ser separada das condições históricas de sua realização. Devem ser contempladas as condições naturais, técnicas, econômicas e sociais (HESSE, 1991, p. 15).

Deve ser igualmente considerado o substrato político e espiritual de determinado povo, ou seja, suas condições sociais concretas e o baldrame axiológico, que influenciam decisivamente a conformação, o entendimento e a autoridade das proposições normativas. A pretensão de eficácia não se confunde com as condições de realização de uma norma, mas associa-se a essas condições como elemento autônomo (HESSE, 1991, p. 15).

Portanto, Hesse (1991, p. 15) esclarece que a Constituição não afigura o que é, mas o que deve ser não se trata de mero reflexo social. Partindo da pretensão de eficácia, a Constituição procura imprimir conformação à realidade: 
Determinada pela realidade social e, ao mesmo tempo, determinante em relação a ela, não se pode definir como fundamental nem a pura normatividade, nem a simples eficácia das condições sócio-políticas e econômicas. A força condicionante da realidade e a normatividade da Constituição podem ser diferenciadas; elas não podem, todavia, ser definitivamente separadas ou confundidas.

"Constituição real" e "Constituição jurídica" estão em relação de coordenação constante. Elas condicionam-se mutuamente, mas não dependem uma da outra. A pretensão de eficácia apresenta-se como elemento autônomo no campo das forças do qual resulta a realidade do Estado. A Constituição adquire força normativa na medida em que logra realizar essa pretensão de eficácia. Contudo, não se pode esquecer: as normas constitucionais devem encontrar raízes no substrato político e axiológico de determinado povo.

Humboldt (apud HESSE, 1991, p. 16) entende que somente a Constituição que se vincula a uma situação histórica concreta e suas condicionantes, dotada de uma ordenação jurídica orientada pelos parâmetros da razão, pode desenvolver-se. Esta razão orienta e dirige a realidade disponível. Ela não dispõe de capacidade para produzir substâncias novas. Essa força reside apenas na natureza das coisas; a razão verdadeiramente sábia empresta-lhe estímulo, procurando dirigi-la. Nesse sentido, as Constituições não podem ser impostas aos homens como se enxertam rebentos emárvores.

Humboldt (apud HESSE, 1991, p.18) continua sua reflexão consignando que toda a Constituição deve encontrar um germe material de sua força vital no tempo, nas circunstâncias, no caráter nacional, necessitando apenas de desenvolvimento. Se não quiser condenar-se a esterilidade, a Constituição não deve ser mera construção abstrata e teórica. Deve produzir o que já está assente naquele povo. A norma constitucional adquire poder e prestígio se for determinada pelo princípio da necessidade.

A força vital e a eficácia da Constituição assentam-se na sua vinculação às forças espontâneas e às tendências dominantes do seu tempo, o que possibilita o seu desenvolvimento e sua ordenação objetiva. A Constituição converte-se, assim, na ordem geral objetiva do complexo da vida (HESSE, 1991, p. 18).

A Constituição Federal de 1988 atende às premissas teóricas apresentadas por Hesse (1991) vez que reflete e traduz muitos dos valores, da cultura e das necessidades sociais do Brasil. Porém, a questão não se esgota aqui. Segundo Hesse (1991, p. 19), a força normativa da Constituição não reside, tão somente, na adaptação inteligente a uma dada realidade. A Carta transforma-se em força ativa se existir disposição em orientar as próprias condutas segundo a ordem nela estabelecida, se houver a Vontade de Constituição. A Constituição não pode por si só realizar nada. Mas pode impor tarefas. Assim entende Hesse (1991, p.19):

A Constituição transformar-se em força ativa se essas tarefas forem efetivamente realizadas, se existir disposição de orientar 
a própria conduta segundo a ordem nela estabelecida, se, a despeito de todos os questionamentos e reservas provenientes dos juízos de conveniência, se puder identificar a vontade de concretizar essa ordem. Concluindo, pode-se afirmar que a Constituição converter-se-á em força ativa, se fizerem-se presentes na consciência geral - particularmente, na consciência dos principais responsáveis pela ordem constitucional - não só a vontade de poder (Wille zur Macht), mas também a vontade de Constituição (Wille zur Versaffung).

O autor (1991, p. 20) desenvolve seu argumento de efetividade constitucional baseando-se na Vontade de Constituição, originada em três fundamentos: compreensão da necessidade e do valor de uma ordem jurídica inquebrantável, que proteja o Estado contra o arbítrio desmedido e disforme; compreensão de que essa ordem constituída é mais do que uma ordem legitimada pelos fatos, logo, precisa estar em constante processo de legitimação; e,consciência de que, ao contrário do que se dá com uma lei do pensamento, essa ordem não logra ser eficaz sem o concurso da vontade humana. Essa ordem adquire e mantém sua vigência por meio de atos de vontade. (HESSE, 1991, p.20).

A vida do Estado, tal como a vida humana, não está abandonada à ação surda de forças inelutáveis. Ao contrário, todos estão convocados a dar conformação à vida do Estado, assumindo as tarefas por ele colocadas. O desenvolvimento da força normativa da Constituição depende não apenas de seu conteúdo, mas de sua práxis (HESSE, 1991, p. 19-23):

Todos os interesses momentâneos - ainda quando realizados não logram compensar o incalculável ganho resultado do comprovado respeito à Constituição, sobretudo naquelas situações em que sua observância revela-se incômoda. Como anotado por Walter Burckhart, aquilo que é identificado como Vontade de Constituição deve ser honestamente preservado, mesmo que, para isso, tenhamos de renunciar a alguns benefícios, ou até a algumas vantagens justas. Quem se mostra disposto a sacrificar um interesse em favor da preservação de um princípio constitucional, fortalece o respeito à Constituição e garante um bem da vida indispensável à essência do Estado, mormente ao Estado democrático. Aquele que, ao contrário, não se dispõe a esse sacrifício, malbarata, pouco a pouco, um capital que significa muito mais do que todas as vantagens angariadas, e que, desperdiçado, não mais será recuperado.

Para ele, a interpretação adequada é aquela que consegue concretizar, de forma excelente, o sentido da proposição normativa dentro das condições reais dominantes numa determinada situação. Ressalva o autor que uma mudança nas relações fáticas pode e deve provocar mudanças na interpretação da Constituição. A própria proposição jurídica estabelece o limite da interpretação e o limite de qualquer mutação normativa. A intensidade da força normativa apresenta-se, em 
primeiro plano, como uma questão de vontade normativa, de Vontade de Constituição (HESSE, 1991, p. 23-24).

A proposição teórica de Hesse, baseada em um fator volitivo que deve guiar os destinatários das normas constitucionais a observá-las, representa uma grande contribuição para o aprofundamento da compreensão da normatividade constitucional. Todavia, são poucas as vontades de constituição presentes no Estado Brasileiro e há uma forte ausência de articulação política entre esses fatores volitivos, de forma que venham a representar, de fato, uma possibilidade de concretização constitucional.

Por isso a necessidade de se vivificar os espaços políticos, públicos, de mobilização social e política, nas formas colocadas nos tópicos anteriores. Esse elemento político articulador cria e recria entre as pessoas a Vontade de Constituição e é essencial para que ocorra efetividade constitucional. A política proporciona a ocorrência de um maior reconhecimento dos destinatários da Carta com o conteúdo do texto constitucional e difunde uma verdadeira política de práxis constitucional.

Nesse sentido, a teoria de Peter Haberle é extremamente relevante. Conforme já dito, embora partam de fundamentos teóricos distintos, as teorias de Hesse e Haberle podem ser relacionadas no âmbito deste artigo, vez que Hesse consigna com grande força que a intensidade da força normativa da Constituição, reside, em primeiro plano justamente na Vontade de Constituição, que é a adaptação dos comportamentos, mediante atos de vontade ao consagrado constitucionalmente. Haberle, com sua tese sobre a "Sociedade aberta aos intérpretes da Constituição", desenvolvida em 1975, assevera que tendo em vista o papel fundante da Constituição para a sociedade e para o Estado, todo aquele que vive a Constituição é um seu legítimo intérprete.

Haberle atribui legitimidade ainda maior à Vontade de Constituição de Hesse. Os autores trabalham com um argumento comum de efetividade constitucional, fundado na possibilidade da sociedade, composta pelos participes da vida constitucional, como apregoa Hesse, efetivar a Constituição, mediante sua interpretação. Não dirigem apenas suas teorias de efetividade constitucional para os Poderes Públicos, mas abarcam a sociedade como um elemento indispensável para a salvaguarda do conteúdo constitucional.

Haberle (1997, p. 09) propugna pela adoção de uma hermenêutica constitucional adequada à sociedade pluralista ou à chamada sociedade aberta. Essa concepção exige uma radical revisão da metodologia jurídica tradicional, que esteve sempre muito vinculada ao modelo de uma sociedade fechada, reduzindo seu âmbito de investigação na medida em que se concentra, primariamente, na interpretação constitucional dos juízes, e nos procedimentos formalizados. Ao revés, cidadãos e grupos de interesse, órgãos estatais, o sistema público e a opinião pública constituiriam forças produtivas de interpretação, atuando, pelo menos, como préintérpretes do complexo normativo-constitucional. 
Não existe norma jurídica, senão norma jurídica interpretada. Interpretar um ato normativo nada mais é do que colocá-lo no tempo ou integrá-lo na realidade pública (HABERLE, 1997, p. 12):

\begin{abstract}
Se se considera que uma teoria da interpretação constitucional deve encarar seriamente o tema "Constituição e realidade constitucional" - aqui se pensa na exigência de incorporação das ciências sócias e também nas teorias jurídico-funcionais, bem como nos métodos de interpretação voltados para atendimento do interesse público e do bem estar geral - então há de se perguntar, de forma mais decidida, sobre os agentes conformadores da "realidade constitucional".
\end{abstract}

Nesse sentido, o conceito de interpretação reclama esse esclarecimento: quem vive a norma, acaba por interpretá-la ou pelo menos co interpretá-la. Toda a atualização da Constituição, por meio de qualquer indivíduo, constitui, ainda que parcialmente, uma interpretação constitucional antecipada. Originariamente, indicase como interpretação apenas a atividade consciente dirigida à compreensão de sentido de uma norma. A questão do método se impõe quando se tem este tipo de interpretação intencional (HABERLE, 1997, p, 14).

Para Haberle (1997, p. 16), uma pesquisa ou investigação realista do desenvolvimento da interpretação constitucional, torna exigível um conceito mais amplo de hermenêutica: cidadãos e grupos, órgãos estatais, o sistema público e a opinião pública representam forças produtivas de interpretação, atuam, ao menos como pré-intérpretes:

[...] Subsiste sempre a responsabilidade da jurisdição constitucional, que fornece, em geral, a última palavra sobre a interpretação. Se se quiser, tem-se aqui uma democratização da interpretação constitucional. Isso significa que a teoria da interpretação deve ser garantida sob a influência da teoria democrática. Portanto, é impensável uma interpretação da Constituição sem o cidadão ativo e sem as potências públicas mencionadas. Todo aquele que vive no contexto regulado por uma norma e que vive com este contexto é, indireta ou, até mesmo diretamente, um intérprete dessa norma. O destinatário da norma é participante ativo, muito mais ativo do que se pode supor tradicionalmente, do processo hermenêutico. Como são apenas os intérpretes jurídicos que vivem a norma, não detém eles o monopólio da interpretação da Constituição.

Não se trata apenas de práxis estatal, seja do ponto de vista teórico, seja do ponto de vista prático. Ao processo de interpretação têm acesso todas as forças da comunidade política. No caso dos direitos fundamentais já se processa a interpretação no modo como os destinatários da norma preenchem o âmbito de proteção daquele direito (HABERLE, 1997, p. 15-23).

Ainda impera a ideia de que o processo de interpretação constitucional está reduzido aos órgãos estatais, "órgãos oficiais" ou aos participantes diretos de uma 
ação judicial. Não se está a retirar a essencialidade da atividade desenvolvida por estes, mas a ampliar o alcance da interpretação, vez que é uma questão que atinge a todos. Afinal, a Constituição é o fundamento do ordenamento jurídico de um Estado. Os grupos, os próprios indivíduos são considerados intérpretes indiretos ou em longo prazo. A conformação da realidade pela Constituição torna-se também parte da interpretação das normas constitucionais pertinentes a essa realidade (HABERLE, 1997, p. 26).

Até porque não há como se pensar em transformação social, conforme propõe a teoria da Constituição Dirigente, sem considerar uma sociedade articulada, comprometida com a vivência da Constituição. Restringir a aplicação constitucional aos órgãos oficiais estatais significa propor uma transformação social imposta pelo Estado. O Estado é também ator desse processo, ator privilegiado, contudo, não é possível concretizar mudanças confiando apenas em seus mecanismos. Para a Constituição ter sua legitimidade reforçada é necessário comprometimento político e social.

Haberle (1997, p. 26) reconhece que sua teoria pode ser criticada por propiciar que a interpretação constitucional se dissolva em um grande número de intérpretes e interpretações, rompendo com a unidade política que é postulada da Constituição. Apresenta a seguinte ponderação (1997, p. 30):

\begin{abstract}
A estrita correspondência entre vinculação (à Constituição) e legitimação para a interpretação perde, todavia, o seu poder de expressão quando se consideram os novos conhecimentos da teoria da interpretação: interpretação é um processo aberto. Não é pois, um processo de passiva submissão, nem se confunde com a recepção de uma ordem. A interpretação conhece possibilidades e alternativas diversas. A vinculação se converte em liberdade na medida em que se reconhece que a nova orientação hermenêutica consegue contrariar a ideologia da subsunção. A ampliação do círculo de intérpretes aqui sustentada é apenas a conseqüência da necessidade, por todos defendida, de integração da realidade no processo de interpretação. É que os intérpretes em sentido amplo compõem essa realidade pluralista. Se se reconhece que a norma não é uma decisão prévia, simples e acabada, há de se indagar sobre os participantes no seu desenvolvimento funcional, sobre as forças ativas da law in public action (personalização, pluralização da interpretação constitucional).
\end{abstract}

Uma teoria jurídica que fique limitada à lógica normativa perde de vista a vinculação social da jurisdição. A negação da ideologia da subsunção não significa que os órgãos de aplicação do direito devam atuar como geradores de casualidades. A legitimação fundamental das forças pluralistas da sociedade para participar no processo de interpretação reside no fato de que essas forças representam parte da publicidade e da realidade da Constituição. Trata-se de um desdobramento do princípio republicano. A Constituição não estrutura apenas o Estado, mas a sociedade, logo, não pode tratar as forças sociais como meros objetos. Ela deve integrá-las 
ativamente enquanto sujeitos. A práxis atua aqui na legitimação da teoria e não a teoria na legitimação da práxis (HABERLE, 1997, p. 32-33).

Limitar a hermenêutica constitucional aos intérpretes "corporativos" ou autorizados jurídica ou funcionalmente pelo Estado significaria um empobrecimento ou um autoengodo. E isso não retira do Direito Constitucional seu caráter científico. Constituição enquanto objeto é (também) coisa da ciência. A esfera da ciência deve ser considerada como elemento autônomo, mas ao mesmo tempo integrado da comunidade política. Para reforçar sua assertiva, Haberle cita Popper (1997, p. 35):

\begin{abstract}
Para Popper, a objetividade científica não é produto da imparcialidade do cientista, mas resultado do caráter social e público do método científico. A imparcialidade do cientista individualmente, quando existente, não constitui fonte senão resultado dessa objetividade cientifica social ou institucionalmente organizada.
\end{abstract}

Na ciência do Direito Constitucional e nas ciências da realidade, segundo Haberle (1997, p. 36), os cidadãos e os grupos em geral não dispõem de legitimação democrática para a interpretação da Constituição em sentido estrito. É importante recordar que a democracia, regime adotado constitucionalmente no Brasil, não se desenvolve apenas no contexto de delegação de responsabilidade formal do povo para os órgãos estatais.

Em uma sociedade aberta ela se desenvolve mediante formas refinadas de mediação do processo público e pluralista da política, da práxis cotidiana, especialmente mediante a realização dos direitos fundamentais. Democracia se desenvolve mediante a controvérsia sobre alternativas, possibilidades e sobre as necessidades da realidade, bem como sobre aspectos científicos de fundo constitucional, nas quais pode haver interrupção e nas quais não existe e nem deve existir dirigente (HABERLE, 1997, p. 37).

Considerando que a interpretação pluralista constitui-se em uma préinterpretação do texto, os princípios e métodos jurídicos de interpretação constitucional preservam seu significado, exercendo, porém, uma nova função: eles são os "filtros" sobre os quais a força normatizadora da publicidade atua e ganha conformação. Disciplinam e canalizam as múltiplas formas de influência dos diferentes participantes do processo (HABERLE, 1997, p. 44).

Essas reflexões são extremamente pertinentes para a realidade constitucional do Brasil. As noções de força normativa da Constituição e de Constituição Dirigente e compromissória não podem ser relegadas a um plano secundário, mormente em um país em que as promessas da modernidade, contempladas nos textos constitucionais, carecem de uma maior efetividade (STRECK, 2004, p. 323).

Averba Streck (2004, p. 339) que o problema da interpretação jurídica enquanto problema normativo é um problema de concreta realização normativa do Direito. Interpretar é aplicar. Applicatio significa o ponto de estofo do sentido, em que fato é norma e norma é fato.

É nesse contexto que ao tratar-se de interpretação jurídica, deve-se falar em 
interpretação jurídico-concreta (factual). E assim, na medida em que a hermenêutica é o modo de ser, que emerge da faticidade e da existencialidade do intérprete a partir de sua condição de ser-no-mundo, a Constituição não exsurge em sua abstratalidade, a-temporal e a-histórica, alienados do mundo da vida. A Constituição deve ser vivenciada como Constituição e isto dependerá da pré-compreensão do intérprete (STRECK, 2004, p. 340).

Reforça Streck (2004, p. 340, grifo do autor):

[...] compreendemos a Constituição 'como' Constituição quando a confrontamos com a sociedade para qual é dirigida; compreendemos a Constituição 'como' Constituição quando examinamos os dispositivos que determinam o resgate das promessas da modernidade e quando, através de nossa consciência acerca dos efeitos que história tem sobre nós [...], damo-nos conta da ausência de justiça social (cujo comando de resgate está no texto constitucional); compreendemos a Constituição 'como' Constituição quando constatamos que os direitos fundamentais somente foram integrados ao texto constitucional pela exata razão de que a imensa maioria da população não os têm; a Constituição é, também, desse modo, a própria ineficácia da expressiva maioria dos seus dispositivos (que é finalmente, a própria realidade social); percebemos também que a Constituição não é somente um documento que estabelece direitos, mas, mais do que isto, ao estabelecê-los, a Constituição coloca a lume (denuncia, dramaticamente) a sua ausência, desnudando as mazelas da sociedade [...]

Se interpretar é aplicar, não há um pensamento teórico que "flutua" sobre os objetos do mundo, apto a dar sentido ao "mundo sensível". O sentido de algo se dá; ele acontece(STRECK, 2004, p. 359).

Pensar a interpretação nesse sentido amplia o espaço de possível legitimação material da Constituição e devolve a ela elementos que lhe foram subtraídos, como sua capacidade de conexão com a realidade social, política e econômica do país. Se existem forças sociais articuladas politicamente orientadas a viver a Constituição, as transformações sociais prometidas pela Teoria da Constituição Dirigente podem se tornar possíveis. Do contrário, pode-se aguardar inerte a sua derrocada final, levando consigo uma conquista história de garantias e direitos fundamentais.

Os autores acima trabalhados, de modo especial, Hesse e Haberle, trabalham com um argumento comum de efetividade constitucional, fundado na possibilidade da sociedade, composta pelos participes da vida constitucional, como apregoa Hesse, efetivar a Constituição, mediante sua interpretação. Não dirigem apenas suas teorias de efetividade constitucional para os Poderes Públicos, como costumeiramente se faz, mas abarcam a sociedade como um elemento indispensável para a salvaguarda do conteúdo constitucional. De fato, se assim não for, não há que se falar em transformação social, ao menos que se queira sustentar o absurdo de que os direitos fundamentais inscritos na Constituição são imediatamente eficazes para os órgãos 
do Estado, mas não para os particulares (COMPARATO, 1990, p. 33).

Como se verifica, tanto os clássicos da Teoria Constitucional, como também os grandes construtores da Teoria Constitucional brasileira encontram-se assertes na compreensão de que se deve ampliar o círculo de interpretação constitucional. A sociedade civil e os próprios particulares desempenham papel fundamental na vivificação do espaço político brasileiro, construindo uma política cívica, voltada à realização da Constituição.

\section{Considerações Finais}

Tem-se ciência dos limites contidos na Teoria da Constituição Dirigente ${ }^{6}$, conforme demonstrado anteriormente. Contudo, ciência maior se tem de que esta construção teórica não merece ser desqualificada, vez que as transformações sociais que ela ratifica ser possível acontecer por meio da Constituição, são necessárias e esperadas. Desbancar o papel emancipador da Constituição não constitui a melhor alternativa. Uma leitura da Constituição Federal é suficiente para se concluir, de forma primária, que suas previsões são construções culturais de um povo, que retratam suas necessidades, idealidades e utopias maiores.

As condições econômicas, sociais e políticas do Estado Brasileiro exigem reflexões no sentido de se buscarem caminhos, alternativas, para a superação da miserabilidade e da violência estrutural nascida desse círculo vicioso. Do contrário, far-se-á coro com aqueles que professam que o ordenamento jurídico vigente prestase apenas a garantir e perpetuar o atual estado de coisas, em um suposto "quadro de ordem".

O Poder Constituinte é de fato o povo, este não deve se limitar a estabelecer uma Constituição. A existência do povo como instância permanente de legitimação constitucional é fator determinante da força normativa da Constituição.

Até porque, como já colocado anteriormente, não há como se pensar em transformação social, conforme propõe a teoria da Constituição Dirigente, sem considerar uma sociedade articulada, comprometida com a vivência da Constituição. O Estado é também ator desse processo, ator privilegiado, contudo, não é possível concretizar mudanças confiando apenas em seus mecanismos. Para a Constituição ter sua legitimidade reforçada é necessário comprometimento político e social.

A Constituição retrata os valores da sociedade, logo, não contém nenhum absurdo a ser observado. O que é necessário reforçar é a força contida na sociedade civil organizada para a proliferação da práxis constitucional. A partir das teorias de Hesse e Haberle, verifica-se a viabilidade dessa assertiva.

\footnotetext{
${ }^{6}$ Ver, a propósito, CANOLTILHO, José Joaquim Gomes. Rever ou romper com a Constituição Dirigente? Defesa de um constitucionalismo moral reflexivo. Revista dos Tribunais, ano 4, n.15, abril-junho de 1996, p. 6-17.
} 


\section{REFERÊNCIAS BIBLIOGRÁFICAS}

BARROSO, Luís Roberto. O Direito Constitucional e a efetividade de suas normas: limites e possibilidades da Constituição Brasileira. $5 \mathrm{ed}$. ampliada e atual. Rio de Janeiro:Renovar, 2001.

BERCOVICI, Gilberto. Constituição econômica e desenvolvimento. São Paulo: Malheiros Editores, 2005.

. A Constituição Dirigente e a crise da Teoria da Constituição. In: Teoria da Constituição: estudos sobre o lugar da política no direito constitucional. Rio de Janeiro: Lumen Juris, 2003.

. Soberania e Constituição: para uma crítica do constitucionalismo. São Paulo: Editora Quartier Latin, 2008.

A problemática da Constituição Dirigente: algumas considerações sobre o caso brasileiro. Revista da Informação Legislativa 142/35-51, 1999.

CAPELLARI, Eduardo. A crise da modernidade e a constituição: elementos para a compreensão do constitucionalismo contemporâneo. Rio de Janeiro: América Jurídica, 2004.

CANOTLLO, José Joaquim Gomes. Constituição Dirigente e vinculação do legislador: contributo para a compreensão de normas constitucionais programáticas. $2^{\mathrm{a}} \mathrm{ed}$. Coimbra: Coimbra Editora, 2001.

. Rever ou romper com a Constituição Dirigente? Defesa de um constitucionalismo moral reflexivo. Revista dos Tribunais, ano 4, n.15, abril-junho de 1996.

COUTINHO, Jacinto Nelson de Miranda; LIMA, Martonio Mont' Alverne Barreto (orgs). Diálogos constitucionais: direito, neoliberalismo e desenvolvimento em países periféricos. Rio de Janeiro: Renovar, 2006.

COMPARATO, Fábio Konder. A função social da propriedade dos bens de produção. In: Direito empresarial: estudos e pareceres. São Paulo: Saraiva, 1990.

HABERLE, Peter. Hermenêutica constitucional. Porto Alegre: Sergio Antônio Fabris Editor, 1997.

HESSE, Konrad. A força normativa da Constituição. Porto Alegre. Ed. Sérgio Fabris, 1991.

LASSALE, Ferdinand. O que é uma Constituição Política. São Paulo: Global Editora, 1987.

PATEMAN, Carole. Participação e teoria democrática. Rio de Janeiro: Paz e Terra, 1992. 
SANTOS, Boaventura de Sousa. A gramática do tempo: para uma nova cultura política. São Paulo: Cortez, 2006.

STRECK, Lênio Luiz. In: Diálogos Constitucionais Brasil e Portugal. Rio de Janeiro: Renovar, 2004.

VIEIRA, Liszt. Os argonautas da cidadania: a sociedade civil na era da globalização. Rio de Janeiro: Record, 2001.

WOLKIMER, Antonio Carlos. Constitucionalismo e Direitos Sociais no Brasil. São Paulo: Acadêmica, 1989. 